\title{
Development of Malignant Hypertension in Patients with Uremia under Hemodialysis: A Case Report and Discussions on Its Etiology
}

\author{
Hiroshi Kaneda, Toyoaki Murata, Takakichi Maeta, \\ Jun Matsumoto, Kozo Shitomi, Takeshi Haruyama, ${ }^{*}$ \\ Mitsuru Hara $\dagger$ and Haruki Wakasa \\ Clinic of Renal Disease, Iwaki-Kyoritsu General Hospital, \\ Iwaki 973, *Clinic of Internal Medicine, Joban City \\ Hospital, Iwaki 972, †Department of Pathology, Toranomon \\ General Hospital, Tokyo 10\%, and the First Department of \\ Pathology, Fukushima Medical College, Fukushima 960
}

\begin{abstract}
Kaneda, H., Murata, T., Maeta, T., Matsumoto, J., Shitomi, K., Haruyama, T., Hara, M. and Wakasa, H. Development of Malignant Hypertension in Patients with Uremia under Hemodialysis: A Case Report and Discussions on Its Etiology. Tohoku J. exp. Med., 1981, 135 (3), 291-299—A woman, now 28 years old, was diagnosed 6 years ago as chronic glomerulonephritis by renal biopsy. From August 15, 1975 she complained of nausea, loss of appetite and weight (about $7 \mathrm{~kg}$ within 2 weeks). Severe hypertension $(200 / 130 \mathrm{mmHg})$, hyponatremia (123 $\mathrm{mEq} /$ liter), anemia, elevated plasma renin activity (PRA), advanced azotemia, and eye ground changes of KW-II were found. Dialysis treatment was started on September 2, 1975. From November 1975 massive amounts of sodium $(5,000$ $\mathrm{mEq}$ or more monthly) and water (26 liters or more monthly) were removed by the dialysis. These intensive dialyses resulted in an elevated PRA with recurrence of severe hypertension. At the end of March 1976 she became almost blind with retinopathy of $\mathrm{KW}$-IV. Potent hypotensive drugs including $\beta$-blockers were administered, but no improvements were obtained. On March 31, 1976 nephrectomy was performed to save her life. Marked hyalinization of glomeruli and heavy thickening of intima in interlobular arteries were found in the removed kidneys. Renal artery stenosis was not recognized either macroscopically or histologically. In this patient, the amount of sodium removed by the dialysis was dependent on her diastolic blood pressure and sodium concentration of the dialysate. It may be concluded that too enthusiastic dialysis may develop malignant hypertension due to excessive renin release.- malignant hypertension; dialysis treatment; negative sodium balance
\end{abstract}

Since Vorhard and Fahr proposed malignant hypertension as a new clinical syndrome in 1914, 67 years has elapsed. During these periods, Goldblatt (1938) succeeded in making an experimental hypertension, and more recently, measurements of plasma renin activity (PRA) and plasma aldosterone concentration became relatively easy clinical performances. In these situations, the original concept of malignant hypertension was slightly modified, but its validity and clinical significance have been firmly established.

Received for publication, July 21, 1980. 
The Ministry of Health and Welfare, Japan recommended the following criteria for the diagnosis of malignant hypertension in 1971; Group A malignant hypertension - (1) diastolic hypertension constantly higher than $130 \mathrm{mmHg}$, (2) papilledema, (3) advanced renal damage, and (4) poor general conditions accompanied by heart failure or hypertensive cerebrovascular symptoms. Group B malignant hypertension - three of the 4 items mentioned above are positive, and the remaining one falls a little bit short of the criterion.

During the past 8 years, we treated 30 patients with malignant hypertension. in our Dialysis Unit. Twenty-seven out of 30 had already been affected with the disease at the start of the dialysis. The remaining 3 , however, developed the disease during the dialysis treatment. The intervals from the start of dialysis to the appearance of the disease were 4, 4, and 40 months, respectively. The underlying disease was chronic glomerulonephritis in all of them. One of the patients is described in detail below.

The purpose of this paper is to discuss the role of negative sodium balance as a cause of malignant hypertension.

\section{A Case Report}

Since February 1973 a 21-year-old unmarried woman complained of edema on her legs and general fatigue. On May 23, 1973 she caught cold and suffered from cough, sore throat, fever, and rhinorrhea. In her past history, she underwent an acute glomerulonephritis (macrohematuria, hypertension, and profuse proteinuria) at 6 years of age. One of her elder sisters died of uremia at 23 years.

On admission, her blood pressure was $150 / 90 \mathrm{mmHg}$, but thereafter, it fluctuated between 140 to $110 \mathrm{mmHg}$ in systolic and between 70 to $60 \mathrm{mmHg}$ in

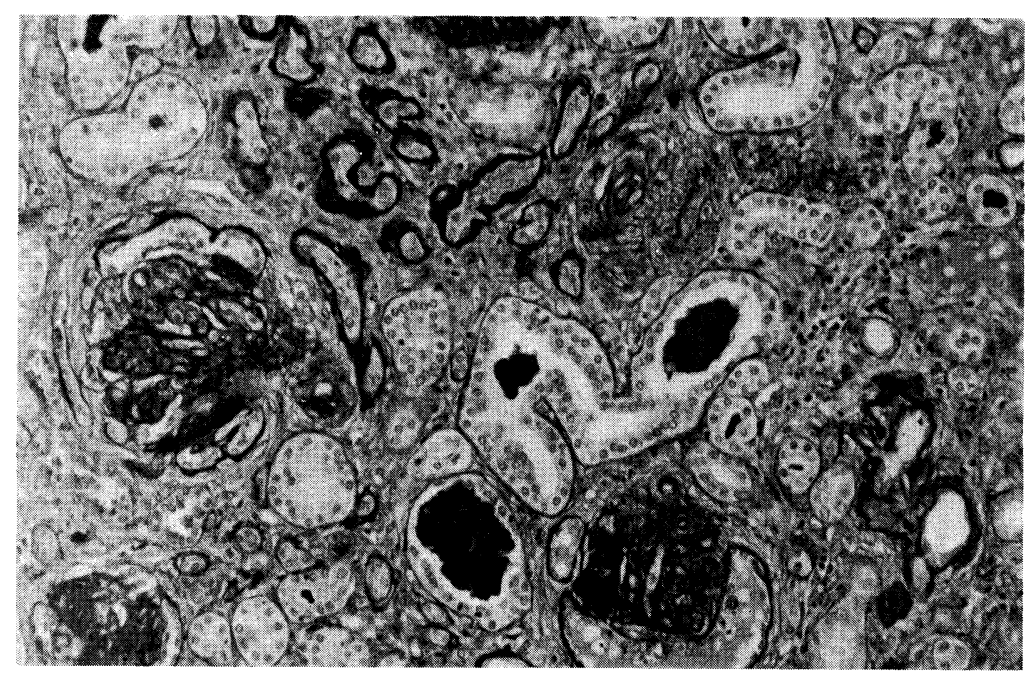

Fig. 1. Renal biopsy on July 4, 1973. Note marked hyalinization of glomeruli. Elastica Masson stain. $\times 80$. 
diastolic. She was $157.2 \mathrm{~cm}$ in height and $42.8 \mathrm{~kg}$ in weight at that time.

The following data were obtained: Deteriorated renal functions (GFR 51.2 $\mathrm{ml} / \mathrm{min}, \mathrm{RPF} 334.0 \mathrm{ml} / \mathrm{min}, \mathrm{RBF} 492.0 \mathrm{ml} / \mathrm{min}$, FF 0.15 , and $24 \mathrm{hr}$ Ccr $46.7 \mathrm{ml} /$ min), slightly atrophic kidneys (right $10.5 \times 6.0 \mathrm{~cm}^{2}$, left $11.5 \times 6.0 \mathrm{~cm}^{2}$ on intravenous pyelography), mild anemia $(\mathrm{Hb} 11.6 \mathrm{~g} / 100 \mathrm{ml}$ ), normal blood urea nitrogen (BUN $9.7 \mathrm{mg} / 100 \mathrm{ml})$, and slightly elevated serum creatinine $(1.7 \mathrm{mg} / 100 \mathrm{ml})$.

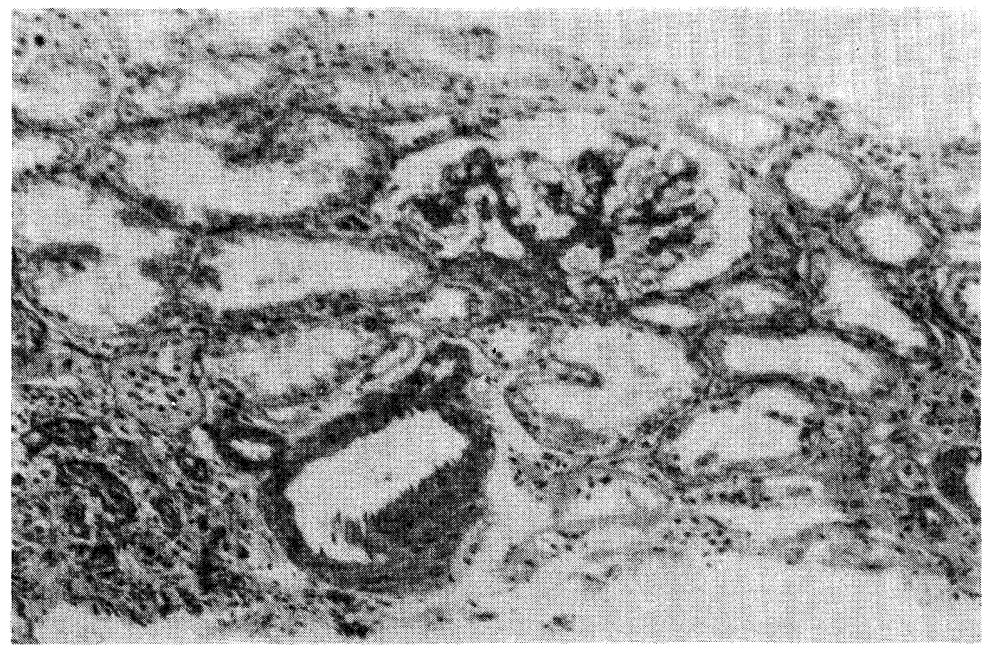

Fig. 2. Interlobular arteries in the same specimen as Fig. 1. Pathological changes are so remarkable. PAS stain. $\times 80$.

Microorganisms (E. coli more than $10^{5}$ per $\mathrm{ml}$ ) were proved in her urine. She was diagnosed as chronic glomerulonephritis associated with acute pyelonephritis.

On July 4, 1973 renal biopsy was done. The histology showed advanced stage of chronic glomerulonephritis (Fig. 1), and insignificant changes in interlobular arteries (Fig. 2).

On August 1, steroid therapy (prednisolone $30 \mathrm{mg}$ /day) was tried against profuse proteinuria ( $3 \mathrm{~g} /$ day or more), but no noticeable improvement was obtained, and on August 23, this therapy was discontinued.

She was discharged on August 27, 1973. Thereafter, she had visited no hospitals nor received any medications. From August 15, 1975 she complained of nausea, loss of appetite, and loss of body weight ( $7 \mathrm{~kg}$ within 2 weeks), and was found to have severe hypertension $(200 / 130 \mathrm{mmHg})$. She was hospitalized again on September 2, 1975.

Laboratory findings on her second admission showed severe hyponatremia (123. $0 \mathrm{mEq} /$ liter), anemia ( $\mathrm{Hb} 4.4 \mathrm{~g} / 100 \mathrm{ml}$ ), elevated PRA $(34.0 \mathrm{ng} / \mathrm{ml})$, elevated lactate dehydrogenase level (779 Wroblewski units; normal range 163-371), advanced azotemia (BUN $68.0 \mathrm{mg} / 100 \mathrm{ml}$, serum creatinine $18.4 \mathrm{mg} / 100 \mathrm{ml}$ ), and retinal change of $\mathrm{KW}$-II.

Plasma renin activity was measured by radioimmunoassay of angiotensin I (Abe et al. 1972, normal range 5.0-30.0 ng/ml). 
Soon after the admission, hemodialysis was started to treat her uremic symptoms. In our Dialysis Unit, the dialysate supplying system was composed of a 50 liters tank and a recirculation system. So, solutes dialysed out of the body were easily measured after every dialysis. Regular dialysis treatment was performed 2 or 3 times per week, and the total dialysis time ranged from 14 to $18 \mathrm{hr}$ per week, using coil or hollow fiber type of dialysers.

Her clinical course from admission to the day of nephrectomy (March 31, 1976) is shown in Fig. 3, in which are illustrated the treatments, blood pressure, serum sodium concentration, PRA, $\triangle \mathrm{PRA} /$ removed-sodium, monthly removed sodium, monthly removed water, body weight, and daily urine volume.

Marked hyponatremia, elevated PRA, and elevated ratio of $4 \mathrm{PRA} /$ removedsodium were improved by the dialyses using high sodium dialysate concentrations (143 mEq/liter or more) in September 1975. Her blood pressure was moderately high from August to December 1975, but from January 1976 it elevated to a high level. In accordance with this blood pressure elevation, PRA, $4 \mathrm{PRA} / \mathrm{rem}$ ovedsodium, and monthly removed sodium was strongly elevated.

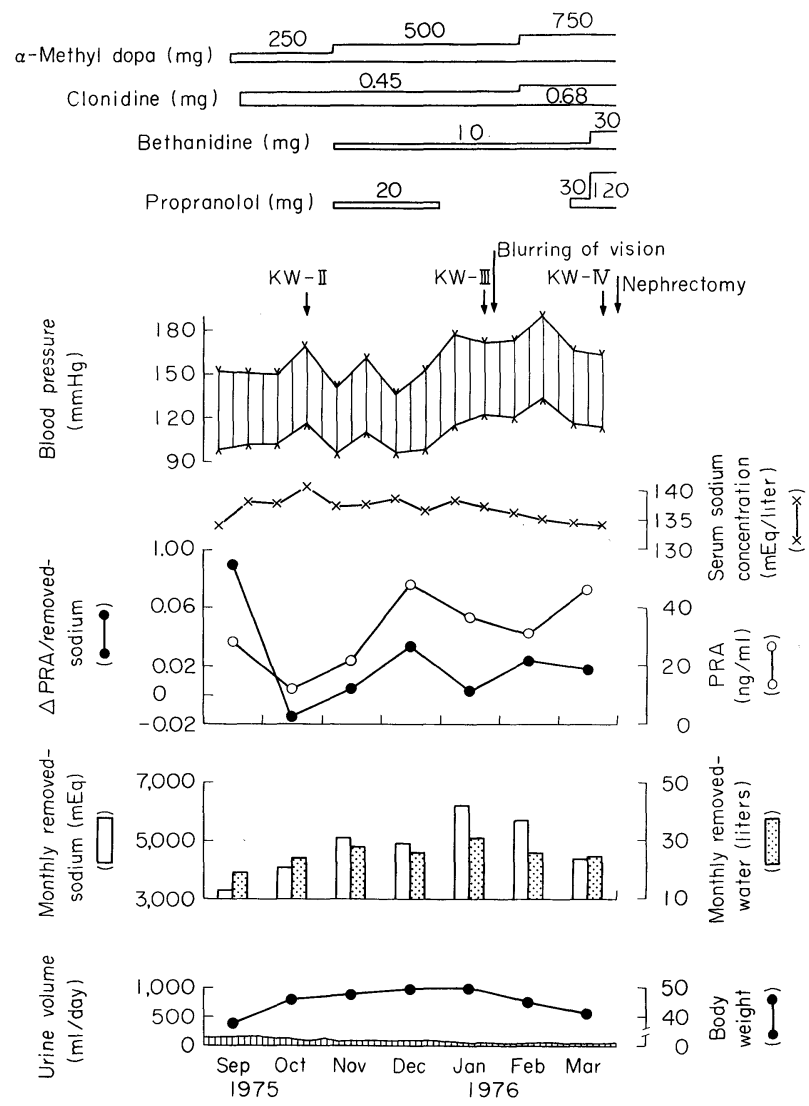

Fig. 3. The clinical course of the patient. 
On the other hand, serum sodium concentration and body weight were decreased. From September 1975 to January 1976, the amounts of sodium and water removed by each dialysis were increased progressively.

On September 26, 1975 her eye grounds showed KW-II but on January 26, 1976 they progressed to KW-III, and further to KW-IV on March 25, 1976.

From the end of January 1976 she complained of blurring of vision, and since the beginning of March she had lost her vision almost completely. She complained of strong prostration, loss of appetite, and dyspnea, suggesting an impending hypertensive heart failure.

In spite of administration of potent hypotensive drugs together with large doses of $\beta$-blocker and adequate dialysis treatment, neither her blood pressure nor elevated PRA was improved, but rather worsened. To save her life, bilateral nephrectomy was done on March 31, 1976.

Soon after the operation, hypertension and elevated PRA were lowered to normal or subnormal levels, but neither hyponatremia nor advanced retinal changes (KW-IV) were improved for a while. Her profound prostration also ameliorated. On June 1, 1976 she was discharged as an outpatient.

\section{Histological findings of the kidneys}

The left kidney weighed $60 \mathrm{~g}$ and the right $62 \mathrm{~g}$. Marked hyalinization of glomeruli (Fig. 4) was observed in every section indicating an advanced stage of chronic glomerulonephritis. Interlobular arteries and arterioles in the kidneys showed extreme thickenings of the intima and media (Fig. 5), and the vascular lumens were scarcely recognized.

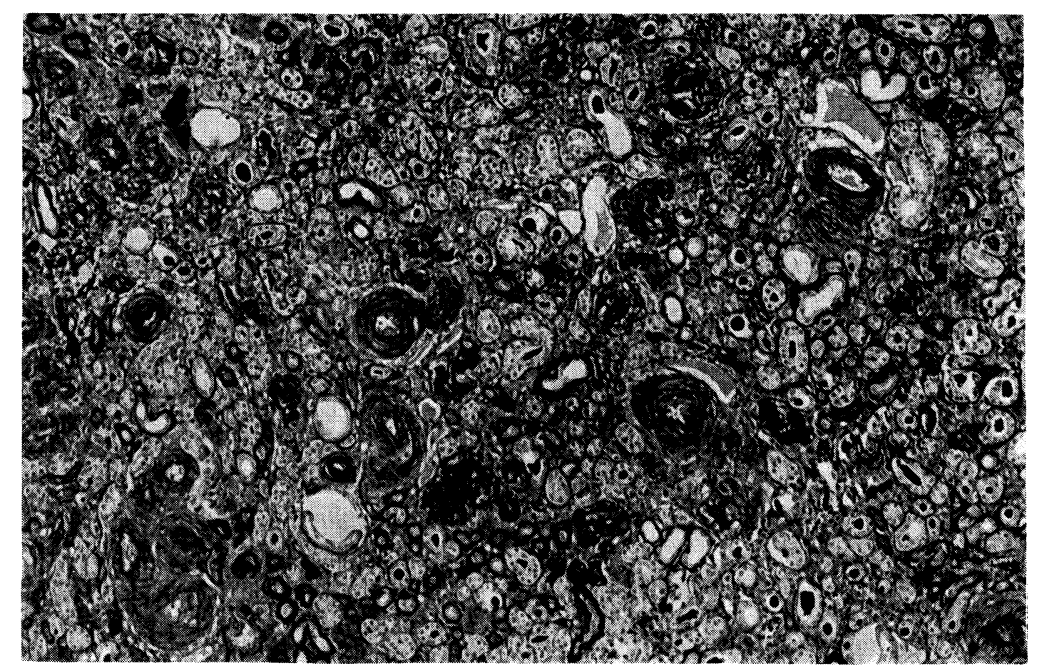

Fig. 4. Microphotograph of the kidney extirpated on March 31, 1976. Hyalinization of glomeruli is noted in the entire areas of section. Elastica Masson stain. $\times 40$. 


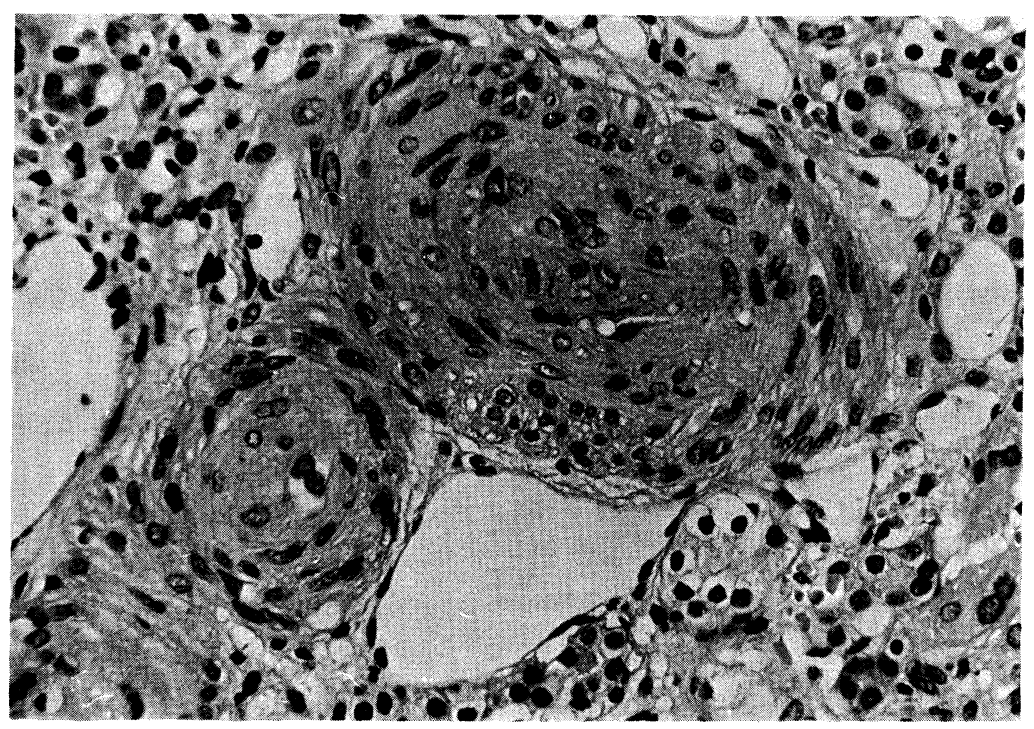

Fig. 5. Interlobular artery and arteriole in the same kidney specimen as Fig. 4. Note marked thickening of the intima and media obliterating the vascular lumen almost completely. PAS stain. $\times 120$.
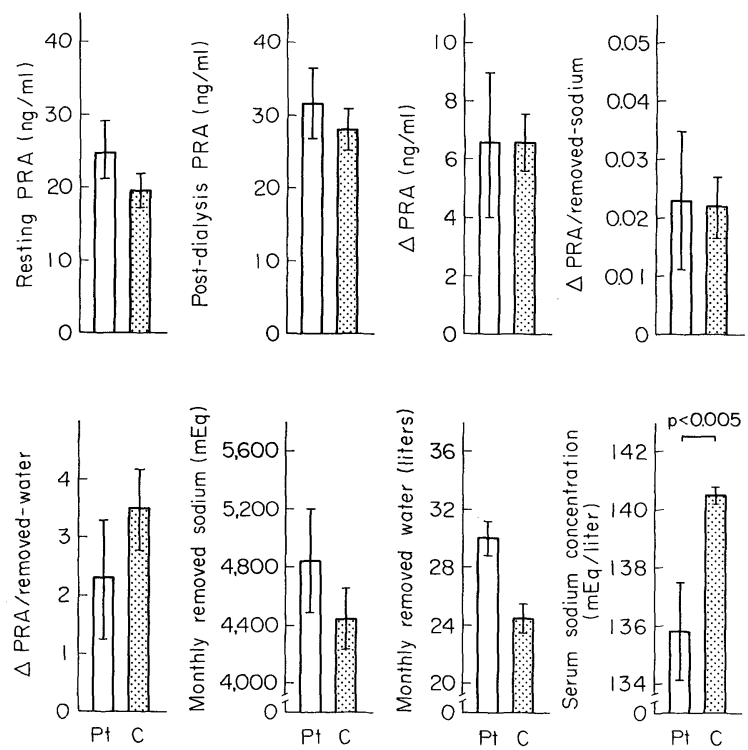

Fig. 6. Laboratory data in the patient (pt) as compared with control patients (C). Mean士s.E.

Relationship between the onset of malignant hypertension and negative sodium balance

Mean values of resting PRA, post-dialysis PRA, $\triangle \mathrm{PRA}, \triangle \mathrm{PRA} /$ removed sodium, APRA/removed-water, monthly removed sodium, monthly removed 
water, and serum sodium concentration measured between the start of dialysis to the day of nephrectomy are shown in Fig. 6 as compared with the control group of patients under hemodialysis. The control group was composed of 61 patients (36 males and 25 females), ranging in age from 15 to 69 years (mean of 42.8). Their duration of dialysis ranged from 3 to 83 months (mean of 19.8), and their underlying diseases were chronic glomerulonephritis (60 patients) and Alport's syndrome (1 patient). In all the control cases, hypotensive medications were stopped at least 1 month before the test.

Mean value of resting PRA was $25.3 \mathrm{ng} / \mathrm{ml}$ in the patient and $19.8 \mathrm{ng} / \mathrm{ml}$ in the control group, and that of post-dialysis PRA was $31.8 \mathrm{ng} / \mathrm{ml}$ in the former and $28.4 \mathrm{ng} / \mathrm{ml}$ in the latter. In neither of the parameters, statistically significant difference was recognized between the patient and control. Mean values of $\triangle \mathrm{PRA}$, $\triangle \mathrm{PRA} /$ removed-sodium, and $\triangle \mathrm{PRA} /$ removed-water were $6.5 \mathrm{ng} / \mathrm{ml}, 0.0233$, and 2.29 respectively, in the patient and $6.6 \mathrm{ng} / \mathrm{ml}, 0.0225$, and 3.51 in the control group. In none of these parameters, statistically significant differences were noted between the patient and control. The mean value of monthly removed sodium was 4,844 $\mathrm{mEq}$ in the patient and $4,451 \mathrm{mEq}$ in the control group. No statistically significant difference was obtained between the two values. The mean value of monthly removed water was 30 liters in the former and 25 liters in the latter; the difference was not statistically significant, either. As for the serum sodium concentration, the mean value was $136 \mathrm{mEq} /$ liter in the former and $141 \mathrm{mEq} /$ liter in the latter; the difference was significant $(p<0.005)$.

\section{Relationship between blood pressure and removal of sodium and water by dialysis}

Table 1 shows the correlation coefficients and the levels of significance between blood pressure and amounts of sodium and water removed by dialysis which were measured 9 times during the periods of 7 months. Diastolic blood pressure correlated significantly with removed sodium $(r=0.67, p<0.05)$, but not with removed water. Neither mean blood pressure nor systolic blood pressure did correlate with removed sodium or water.

Removed sodium correlated negatively with sodium concentration of dialysate $(r=-0.69, p<0.05)$.

\section{Discussion}

It is well known that the clinical course of malignant hypertension is greatly improved by the application of dialysis treatment. On the other hand, it is also known that too enthusiastic dialysis sometimes forces the patients to develop malignant hypertension. Three out of our 30 patients developed malignant hypertension after the dialysis treatment was started. We assume that the conversion of normotensive or moderately hypertensive state to malignant hypertension may sometimes result from the dialysis treatment itself.

We intended to make clear the relationship between the onset of malignant hypertension and the negative sodium balance induced by dialysis in one of the 3 
TABLE 1. The correlation coefficients and the levels of significance between blood pressure and amounts of removed substances after hemodialysis

\begin{tabular}{|c|c|c|c|}
\hline & $\begin{array}{l}\text { Number of } \\
\text { examinations }\end{array}$ & $\begin{array}{l}\text { Correlation } \\
\text { coefficient } \\
(r)\end{array}$ & $\begin{array}{c}\text { Level of } \\
\text { significance } \\
(p)\end{array}$ \\
\hline \multicolumn{4}{|l|}{ Systolic blood pressure } \\
\hline vs Resting PRA & 9 & -0.503 & n.s. \\
\hline Removed sodium by the dialysis & 9 & 0.411 & n.s. \\
\hline Removed water by the dialysis & 9 & 0.033 & n.s. \\
\hline \multicolumn{4}{|l|}{ Diastolic blood pressure } \\
\hline vs Resting PRA & 9 & -0.090 & n.s. \\
\hline Removed sodium by the dialysis & 9 & 0.671 & $<0.05$ \\
\hline Removed water by the dialysis & 9 & 0.639 & $<0.1$ \\
\hline \multicolumn{4}{|l|}{ Mean blood pressure } \\
\hline vs Resting PRA & 9 & -0.306 & n.s. \\
\hline Removed sodium by the dialysis & 9 & 0.654 & $<0.1$ \\
\hline Removed water by the dialysis & 9 & 0.449 & n.s. \\
\hline \multicolumn{4}{|l|}{ Resting PRA } \\
\hline \multicolumn{4}{|l|}{ Sodium concentration of dialysate } \\
\hline \multirow{2}{*}{$\begin{array}{l}\text { vs Removed sodium by the dialysis } \\
\text { Removed water by the dialysis }\end{array}$} & 9 & -0.693 & $<0.05$ \\
\hline & 9 & -0.265 & n.s. \\
\hline
\end{tabular}

patients mentioned above.

From the patient studied here, 5,000 $\mathrm{mEq}$ or more of sodium and 30 liters or more of water had been removed monthly since December 1975. In consequence of such extraordinary removal of sodium and water, PRA and $\triangle \mathrm{PRA} /$ removedsodium increased with resultant severe hypertension, hyponatremia, and body weight reduction. These secondarily induced hypertension promoted further the removal of sodium and water by dialysis resulting in an acceleration of negative sodium balance establishing a vicious circle. From these results, it was likely that the onset of malignant hypertension in the present patient was triggered by the negative sodium balance as a result of extreme removal of sodium and water by the dialysis.

Möhring et al. (1975a, b, 1976), Barraclough (1966), and Kramer et al. (1974) emphasized that the presence of renal artery stenosis is essential for the onset of malignant hypertension in rats and that the excess sodium and water excretion is a secondary phenomenon. In our case, however, renal artery stenosis was not recognized either macroscopically or histologically. Ten patients with malignant hypertension (involving the patient in question) were studied histologically (5biopsy, and 5-autopsy) in our Clinic, but no arterial stenosis was found in renal arteries or their branches. From these experiences, it may be assumed that renovascular stenosis does not seem to be essential for the onset of malignant hypertension (Kaneda et al. 1980). 


\section{Acknowledgment}

We gratefully acknowledge Prof. Kaoru Yoshinaga, the Second Department of Internal Medicine, Tohoku University School of Medicine, Sendai, for his advice on this study. Our thanks are also due to Dr. Yasuo Hatakeyama, Director of Iwaki-Kyoritsu General Hospital, Iwaki, and Dr. Nobuhide Mimura, Director of the Department of Nephrology, Toranomon General Hospital, Kanagawa.

\section{References}

1) Abe, K., Otsuka, Y., Saito, T., Chim, B.S., Aoyagi, H., Miyazaki, S., Irokawa, N., Seino, M., Miura, T., Ono, I., Minai, K., Kobayashi, K., Sato, T. \& Yoshinaga, K. (1972) Measurement of plasma renin activity by angiotensin I radioimmunoassay: a modification of Haber's method. Jap. Circulat. J., 36, 741-749.

2) Barraclough, M.A. (1966) Sodium and water depletion with acute malignant hypertension. Amer. J. Med., 40, 265-272.

3) Goldblatt, H. (1938) The production of malignant phase of hypertension. J. exp. Med., 67, 809-825.

4) Kaneda, H., Yamauchi, T., Murata, T., Matsumoto, J. \& Haruyama, T. (1980) Treatment of malignant hypertension with infusion of sodium chloride. A case report and a reivew. Tohoku J. exp. Med., 132, 179-186.

5) Kramer, P., Köthe, E. \& Scheler, F. (1974) Hyponatriämisch-Hypertone Krise. Klin. Wschr., 52, 787-791.

6) Möhring, J., Möhring, B., Nauman, H., Philippi, A., Homsy, E., Orth, H., Dauda, G., Hazda, S. \& Gross, F. (1975a) Salt and water balance and renin activity in renal hypertension of rats. Amer. J. Physiol., 228, 1847-1855.

7) Möhring, J., Möhring, B., Petri, M., Haack, D. \& Hackenthal, E. (1975b) Studies on the pathogenesis of the malignant course of renal hypertension in rats. Kidney. Int., 8, 174-180.

8) Möhring, J., Petri, M., Szokol, M., Haack, D. \& Möhring, B. (1976) Effects of saline drinking on malignant course of renal hypertension in rats. Amer. J. Physiol., 230, 849-857.

9) Vorhard, F. \& Fahr, T. (1914) Die Brightsche Nierenkrankheit. Julius Springer, Berlin. 